\title{
Genetics of a Drosophila phenoloxidase
}

\author{
T.M. Rizki, R.M. Rizki, and R.A. Bellotti \\ Division of Biological Sciences, The University of Michigan, Ann Arbor, MI 48109, USA
}

\begin{abstract}
Summary. An electrophoretic mobility variant of phenoloxidase in a $l z$ stock of Drosophila melanogaster was identified as the $\mathrm{A}_{3}$ component of the phenoloxidase complex by using two different activators to study enzyme activity - natural activator isolated from pupae and 50\% 2-propanol. The structural gene for the $\mathrm{A}_{3}$ proenzyme, Dox-3, was not associated with $l z$ on the $\mathrm{X}$ chromosome; it mapped to the right of $r d o$ (53.1) and left of $M(2) m$ in the second linkage group.

The $l z$ locus affects the differentiation of the crystal cell, the type of hemocyte that carries prophenoloxidase(s) in paracrystalline form. Alleles of $l z$ lacking paracrystalline inclusions in their hemocytes do not have phenoloxidase activity whereas alleles with paracrystalline inclusions have enzyme activity. The presence of proenzyme in the paracrystalline inclusions was demonstrated by in situ activation with natural activator or propanol followed by incubation in buffered dopa.
\end{abstract}

\section{Introduction}

Insect phenoloxidases are involved in cuticular sclerotization and melanin formation for would healing or cellular defense reactions in the hemocoel (Brunet 1980; T.M. Rizki and R.M. Rizki 1984). These proteins exist as inactive precursors that are converted to active enzyme in vitro by a variety of protein denaturants and proteolytic enzymes (Ashida and Dohke 1980). The phenoloxidase system in Drosophila is particularly complex since it contains not one but four proenzymes: the three $A$ components $\left(A_{1}, A_{2}\right.$, $A_{3}$ ) activated in vitro by a natural activator isolated from pupae (Mitchell and Weber 1965; Seybold et al. 1975) and PHOX activated in vitro by 2-propanol (Batterham and McKechnie 1980). The structural gene for PHOX is located on the second chromosome at 80.6 , but the structural genes for the A components have not been identified. A number of genes, such as tyrosinase-1 (tyr-1; 2-52.4), lozenge (lz; $1-27.7)$ and speck $(s p ; 2-107)$ affect the activity levels of both the A components and PHOX (Lewis and Lewis 1963; Peeples et al. 1969; Warner et al. 1975; Batterham and McKechnie 1980). During a survey of phenoloxidase activity in $l z$ mutants we found an electrophoretic mobility variant of the $A_{3}$ component. This report establishes the position of the structural gene for the $A_{3}$ proenzyme on the linkage map, and describes differences in the activation of

Offprint requests to: T.M. Rizki the Drosophila prophenoloxidases by natural activator and alcohol.

How hemolymph phenoloxidases are related to sclerotization of the cuticle is not understood. Nor is it known whether components of the phenoloxidase system are partitioned such that different protein subsets are active in different tissues. In Drosophila, hemolymph phenoloxidase is present in one type of larval blood cell, the crystal cell, that contains large cytoplasmic paracrystalline inclusions (Rizki 1956). An early study suggested that phenoloxidase is located in the cytoplasm but not the paracrystalline inclusions in these hemocytes (Rizki and Rizki 1959). When crystal cells were later examined by electron microscopy, it became apparent that, depending on the fixation methods used, the paracrystalline inclusions disintegrate, leaving empty spaces surrounded by well-preserved cytoplasm (T.M. Rizki and R.M. Rizki 1984). In view of these observations, we reexamined the intracellular distribution of phenoloxidases in the crystal cells and report the observations here.

\section{Materials and methods}

From the group of $l z$ stocks which have paracrystalline inclusions in their crystal cells (Rizki and Rizki 1981) we selected $l z^{\mathrm{g}}, l z^{34 \mathrm{k}}$, and $l z^{50 \mathrm{e} 30}$. Females carrying the latter allele are fertile. Two alleles that do not result in hemocytes with paracrystalline inclusions were used, $l z^{\mathrm{rfg}}$ and $l z^{\mathrm{s}}$.

The following stocks were used in this study: wild-type Ore- $R, C y / P m ; D / S b$, and al $d p b$ pr c px sp from our laboratory; $l z^{34 \mathrm{k}}, b$ tyr-1, y sc $l z^{\mathrm{g}}$ vf, In49 $l z^{\mathrm{s}}, M(2) z$ In(2LR)SM5, dp ${ }^{2} C y$ b pr, M(2)S4/SM1, al ${ }^{2} C y \mathrm{cn}^{2} s p^{2}$, and $r d o h k p r$ from the Mid-America Drosophila Stock Center; $l z^{50 \mathrm{e} 30}$ from Dr. M.M. Green; $l z^{\mathrm{rg}}$ from Dr. E. Grell; deficiencies $D f(2 L): h k^{18}$ (formerly designated $S D$ $72^{\mathrm{d} 18}$ ), TWl30 pr cn, VA13 $\mathrm{pr}^{-}$cn bw, $150 \mathrm{pr}^{-} \mathrm{cn} \mathrm{bw}, \mathrm{H} 20$ b pr cn sca, TW202, $T W 119$, and $M-H^{\mathrm{s}}$ from Dr. T.R.F. Wright (Wright et al. 1976); deficiencies $D f(2 L): 64 J$ and $75 C$ from Dr. R.C. Woodruff (Woodruff and Ashburner 1979). (For a description of markers, see Lindsley and Grell 1968; for $l z^{\mathrm{rfg}}$, see Warner et al. 1974). The source and the phenotype of the $t u(1) S z^{\text {ts }}$ melanotic tumor strain have been described previously (Rizki and Rizki 1980).

Late third instar larvae grown at $24^{\circ} \mathrm{C}$ on standard cream of wheat/molasses medium were used for electrophoretic analysis and examination of prophenoloxidase in hemocytes. Crosses for mapping experiments were made in 
half-pint bottles containing standard corn meal/agar medium.

All stocks used for the genetic analyses, and the $t u(1) S z^{\text {ts }}$ strain that served as the control for the hemocyte studies, were examined to verify that the electrophoretic mobilities of their prophenoloxidases did not differ from wild-type $O r e-R$ enzymes. The electrophoretic phenotypes of the stocks, including those used in mapping studies, were established by disk gel electrophoresis with 2-propanol as the activator of prophenoloxidase. Slab gel electrophoresis was used for side-by-side comparison of activation by 2propanol and natural activator (P-activator). The electrode buffer in the first series of experiments was $0.082 \mathrm{M}$ Tris/ $0.067 \mathrm{M}$ glycine at $\mathrm{pH} 8.9$. When it was found that resolution was improved by use of $0.01 \mathrm{M}$ sodium tetraborate buffer at $\mathrm{pH} 9.0$, this buffer was adopted to complete the study. For the Tris-glycine system 25 larvae were homogenized in $0.5 \mathrm{ml}$ urea/sucrose/bromophenol blue solution (Warner et al. 1974); for the sodium tetraborate system the larvae were homogenized in a mixture of $8 \%$ sucrose, $0.002 \%$ bromophenol blue, and $0.06 \mathrm{M}$ Tris-citrate buffer at $\mathrm{pH}$ 6.8. Larvae were homogenized using three strokes of a glass-glass homogenizer and homogenates were centrifuged at $18,000 \mathrm{~g}$ for $5 \mathrm{~min}$ (Mitchell and Weber 1965). Aliquots of the supernatants, equivalent to 1.25 larvae, were electrophoresed through a $3 \%$ acrylamide stacking gel and a $6.5 \%$ separating gel (acrylamide: bisacrylamide, 29:1) polymerized by addition of $0.03 \%$ ammonium persulfate.

For disk electrophoresis runs were made at $2.5 \mathrm{~mA}$ per gel tube for $1.5 \mathrm{~h}$ at $4^{\circ} \mathrm{C}$. The proenzymes in the gels were activated with $50 \%$ 2-propanol in $0.1 \mathrm{M}$ potassium phosphate buffer $\mathrm{pH} 6.3$ at $4^{\circ} \mathrm{C}$ for $2 \mathrm{~h}$ (Batterham and McKechnie 1980). After a 30 min rinse in distilled $\mathrm{H}_{2} \mathrm{O}$ at room temperature, the gels were incubated in L-3,4-dihydroxyphenylalanine (dopa) at a concentration of $0.4 \mathrm{mg} /$ $\mathrm{ml}$ in potassium phosphate buffer at $37^{\circ} \mathrm{C}$ (Mitchell and Weber 1965). Activity bands appeared within an hour but the gels were usually incubated overnight to assure maximum blackening.

Slab gels measuring $14 \times 14 \mathrm{~cm} \times 1.5 \mathrm{~mm}$ were run at $10 \mathrm{~mA}$ in a refrigerator at $4^{\circ} \mathrm{C}$ until the dye front had moved $6.5 \mathrm{~cm}$ through the separating gel. Gels were cut so that the proenzymes in some lanes were activated in buffered propanol and other lanes were incubated in Pactivator prepared from 2- to 3-day-old pupae according to the procedures of Mitchell and Weber (1965) and Warner et al. (1974). Activation in propanol was done as described above. Gels treated with $\mathrm{P}$-activator for $3 \mathrm{~h}$ at $4^{\circ} \mathrm{C}$ were rinsed in phosphate buffer at $4^{\circ} \mathrm{C}$ for $10 \mathrm{~min}$. All slab gels were incubated in substrates (dopa or L-tyrosine) on a shaker at room temperature $\left(23^{\circ} \mathrm{C}\right)$. In some experiments $1 \mathrm{mM} \mathrm{Cu}^{++}$was added to the substrate solutions following propanol activation to stain the bands as described by Batterham and McKechnie (1980) for PHOX enzyme. The reactions were terminated by washing the gels in distilled $\mathrm{H}_{2} \mathrm{O}$ and transferring them to $7.5 \%$ acetic acid.

A newly opened bottle of tyrosine (Calbiochem) oxidized after 2-3 weeks. Use of aged tyrosine samples resulted in weak dopa oxidase activity of the A components. The description of enzyme activity in this report is based on fresh tyrosine samples. Hemolymph samples for electrophoresis were collected in Tris-citrate buffer with sucrose (Sigma), applied directly to gels, and electrophoresed using the sodium tetraborate buffer system.
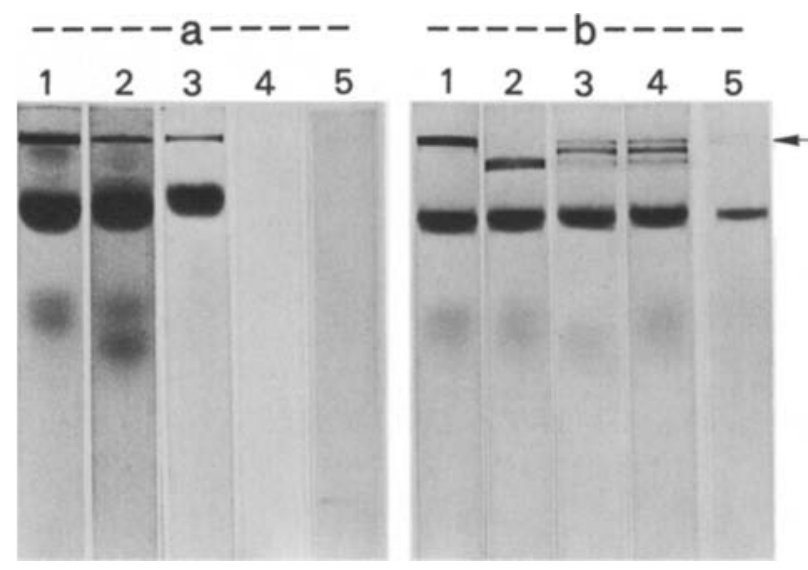

Fig. 1 a, b. Disk gel electrophoresis of Drosophila prophenoloxidases activated by 50\% 2-propanol and incubated overnight in buffered dopa. a 1 , Ore- $R ; 2, l z^{50 \mathrm{e} 30} ; 3, l z^{\mathrm{g}} ; 4, l z^{\mathrm{s}} ; 5, l z^{\mathrm{rg}}$. b 1 , Ore-R;2, lz ${ }^{34 \mathrm{k}} ;$ Dox ${ }^{\mathrm{F}} ; 3$, Ore-R/Dox ${ }^{\mathrm{F}} ; 4$, try-1/Dox ${ }^{\mathrm{F}} ; 5$, tyr-1; the arrow indicates the position of a faint $D o x^{S}$ band in the tyr-1 sample. After overnight incubation in dopa one or two diffuse melanized regions appeared anodal to the major bands

To study the intracellular localization of phenoloxidases, hemocyte samples on microscope slides were fixed in $3.7 \%$ paraformaldehyde in phosphate buffered saline at pH 7.2 (Mishell and Shiigi 1980) for $15 \mathrm{~min}$. Fixative was removed by rinsing the slides in three changes of buffered saline for $3 \mathrm{~min}$ each followed by a $2 \mathrm{~min}$ rinse in phosphate buffer at $\mathrm{pH} 6.3$. Activation in 50\% 2-propanol in phosphate buffer at $\mathrm{pH} 6.3$ was done at room temperature for $20 \mathrm{~min}$ or in P-activator on an ice bath for $20 \mathrm{~min}$. Samples were rinsed in phosphate buffer to remove the activators and transferred to substrates at the same concentrations as above.

\section{Results}

\section{Electrophoretic analysis of lz mutants}

Phenoloxidase activity in cell-free extracts of Ore- $R$ and $l z$ larvae was examined in propanol-activated disk gels. The same two activity bands were present in $O r e-R$ and $l z^{50 e 30}$ male and female extracts, and $l z^{\mathrm{g}}$ male extracts incubated in dopa, but no bands were present in gels with extracts of $l z^{\mathrm{s}}$ and $l z^{\mathrm{rfg}}$ males (Fig. $1 \mathrm{a}$ ). The activity bands appeared within an hour and darkened during overnight incubation at $37^{\circ} \mathrm{C}$. This extended incubation caused blurring of the more anodal band and darkened regions in the lower portion of some gels. Two activity bands were also present in $l z^{34 \mathrm{k}}$ but the less anodal band was a fast variant (Fig. $1 \mathrm{~b}$ ). We refer to this variant as $\mathrm{F}$ (Fast), the variant in Ore- $R$ as $\mathrm{S}$ (Slow), and the gene coding for this proenzyme as Dopa oxidase (Dox).

Males of the $l z^{34 \mathrm{k}}$ stock were mated with Ore- $R$ females, and extracts from the $F_{1}$ larvae were electrophoresed. Both male and female $F_{1}$ larvae had three bands, two with parental mobilities and a darker intermediate band. Hybrid bands are illustrated in Fig. 1b, lane 3. From these observations we conclude: (a) Dox is an autosomal gene so it cannot be associated with the $l z$ locus; (b) this prophenoloxidase is a dimer. A $1: 1$ mixture of $O r e-R$ and $l z^{34 \mathrm{k}}$ larval extracts was electrophoresed and incubated in dopa following propanol activation. The gel showed a fast and a slow band 
and a faint intermediate band indicating that the proenzyme subunits can reassociate in vitro (results not shown).

\section{Mapping the Dox gene}

To determine the linkage group to which Dox belongs, $l z^{34 \mathrm{k}}$ males were crossed with $C y / P m ; D / S b$ females and two stocks subsequently derived from this mating were subjected to electrophoretic analysis: one homozygous for the second chromosome originating from the $l z^{34 \mathrm{k}}$ stock and the other homozygous for the third chromosome of the $l z^{34 \mathrm{k}}$ stock. Since the larvae with the second chromosome of $l z^{34 \mathbf{k}}$ had the $\mathrm{F}$ band, the Dox locus is on the second chromosome.

The lack of useful larval markers for mapping Dox on the second linkage group necessitated an alternative mapping scheme which also did not require single specimens for analysis of enzyme activity. Thus, $F / F ; D / S b$ males were crossed with females from the multiply-marked chromosome 2 stock, "alp" (al dp b pr c px sp), and the $\mathrm{F}_{1}$ "alp"' $+; D /+$ females mated with "alp" males. Non-Dichaete (non- $D$ ) males showing a single exchange between each interval marked by the "alp" genes were singly mated with $M(2) S 4 / S M 1, a l^{2} C y \mathrm{cn}^{2} s p^{2}$ females. In subsequent generations males and females with the $C y$ al phenotype or the $C y s p$ phenotype were chosen to generate stocks which were homozygous for single crossovers in chromosome 2. Thus, 12 stocks representing reciprocal exchanges between the six intervals of the "alp" marker chromosome and the F chromosome were obtained. Electrophoretic analysis of larval extracts from these stocks placed the Dox locus to the right of $b$ and left of $c$.

Males from the $a l d p b F$ stock obtained in the above study were mated with $r$ do $h k \mathrm{pr}$ females, and the $\mathrm{F}_{1}$ females crossed with $M(2) z / \operatorname{In}(2 L R) S M 5 d p^{2} C y b p r$ males. In the next generation crossover males showing the $C y b \mathrm{pr}$ phenotype or the $C y$ phenotype were isolated. Single males were then mated with $C y / P m$ females, and the resulting $C y$ flies were intercrossed to generate homozygous crossover-chromosome stocks. Each stock was analyzed to determine whether the $\mathrm{F}$ or $\mathrm{S}$ variant was present. The $\mathrm{S}$ variant was found with eight recombinants which were al $d p b r d o$ $h k p r$, one recombinant which was al $d p b+h k p r$, and one which was $+++r d o++$. The $\mathrm{F}$ variant was present in one ++++++ recombinant and one $+++r d o++$ recombinant. Among the three single exchanges between $r d o$ and $h k$, two were reciprocal between $r d o$ and Dox, resulting in $r d o F h k^{+} \mathrm{pr}^{+}$and $r d o^{+} S h k$ $p r$, and the third was $r d o S h k^{+} p r^{+}$. Therefore, Dox is located between $r d o$ (53.1) and $h k$ (53.9).

Lewis and Lewis (1963) reported tyr-1 at $52.4 \pm 0.5$ to be a structural gene for phenoloxidase. The enzyme in $t y r-1 /$ tyr-1 is heat labile; the homozygotes also have less enzyme activity. To determine whether Dox is an allele of tyr-1, we electrophoresed cell-free extracts of $F_{1}$ hybrid larvae from a tyr-1 $\mathrm{X}$ Dox $\mathrm{F}^{\mathrm{F}}$ cross and simultaneously electrophoresed $F_{1}$ larvae from a Ore- $R \times D o x^{\mathrm{F}}$ cross as a control. We reasoned that, if $t y r-1$ is allelic to Dox, the $\mathrm{S}$ band in the heterozygotes should have less activity (be lighter) than the F band. The control tyr-1 sample showed less activity as reported by Lewis and Lewis (1963), and the positions of the bands corresponded to those in Ore- $R$ (Fig. $1 \mathrm{~b}$, lane 5). There was no difference in position or activity levels of corresponding bands in $t y r-1 / D o x^{\mathrm{F}}$ and

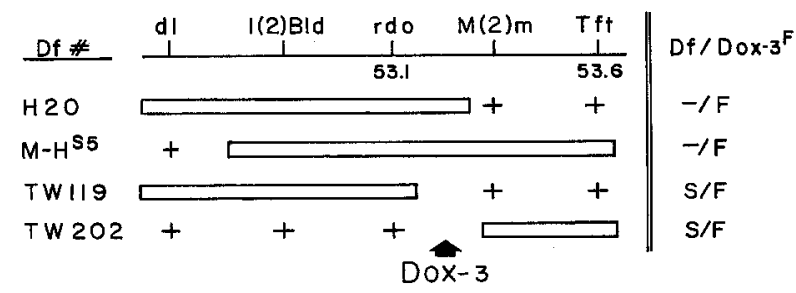

Fig. 2. Deletion mapping of the Dox locus. The extent of the relevant $2 \mathrm{~L}$ deficiencies is indicated by the open bar under the marker genes in the region $d l-T f t$ according to Wright et al. (1976) and Wright (personal communication). Results of the complementation tests between the deficiencies and the fast variant are given in the last column, $D f / D o x-3^{\mathrm{F}} .53 .1$ and 53.6 are the map positions of $r d o$ and $T f t$, respectively; $T f t$ has been mapped $1.2 \mathrm{cM}$ to the left of B1 at 2-54.8 (Tokunaga 1967). Heterozygotes for Dox ${ }^{\mathrm{F}}$ and deficiencies $h k^{18}, V A 13, T W 150$, and $T W 130$ (Wright et al. 1976) to the right of the above interval, and $D f(2 L) 75 c$ and $D f(2 L) 64 j$ (Woodruff and Ashburner 1979) to the left of this interval had the $\mathrm{S} / \mathrm{F}$ phenotype

Ore-R/Dox ${ }^{\mathrm{F}}$ hybrids (Fig.1 b). Since the map positions for tyr-1 and Dox differ and the mutations are complementary in trans-heterozygotes, these genes are not allelic.

A set of overlapping deficiencies was used to locate the position of the Dox gene. Males from each $D f(2 L) / C y$ stock were crossed with $\mathrm{F} / \mathrm{F}$ females and the non- $C y \mathrm{~F}_{1}$ males were mated with $F / F$ females. Larvae from these matings were analyzed for the presence of the $F$ and $S$ allele. The deficient chromosomes were scored as complementary if hybrid bands were present and non-complementary if only the $\mathrm{F}$ band appeared in the gels. The results of the deficiency mapping are summarized in Fig. 2. The $r$ do locus is missing in Df TW119 but Dox is present since heterozygotes showed hybrid bands, S/F. Deficiency $M-H^{\mathrm{s} 5}$ lacks $r d o$ and $\operatorname{Dox}(-/ \mathrm{F}$, phenotype $\mathrm{F}$ variant), and places the Dox locus to the right of the proximal break of $T W 119$. Deficiency $H 20$ lacks Dox $(-/ F)$ but has $M(2) m^{+}$since it is not phenotypically minute, therefore, Dox is left of the $M(2) m$ region. Finally, TW202, which does not delete Dox but does delete $M(2) m^{+}$, unambiguously places the Dox locus between $r d o$ and $M(2) m$. Therefore, the map position of Dox is $>53.1$ and <53.6, the Tft locus; the map position of $M(2) m$ has not been established.

\section{Identification of the A components coded by Dox}

Using activator preparations isolated from pupae, Mitchell and Weber (1965) found three phenoloxidases in D. melanogaster, one proenzyme which had primarily monophenoloxidase activity $\left(A_{1}\right)$ and two dopa oxidases $\left(A_{2}\right.$ and $\left.A_{3}\right)$. The electrophoretic mobility of the $A_{3}$ component differed only slightly from that of $\mathrm{A}_{2}$ even though the proenzymes were separable by ammonium sulfate precipitation. Since propanol activation resolved only two bands, the question remained whether propanol was unable to activate the third A component or our method of electrophoresis was not separating the three proenzymes. We prepared natural activator from pupae and switched to slab gels to compare the effects of both activators on samples electrophoresed side by side.

Slab gels with Ore- $R$ proenzymes activated by P-activator showed three activity bands following incubation in dopa (Fig. 3, lane 2). Similar gels incubated in tyrosine 


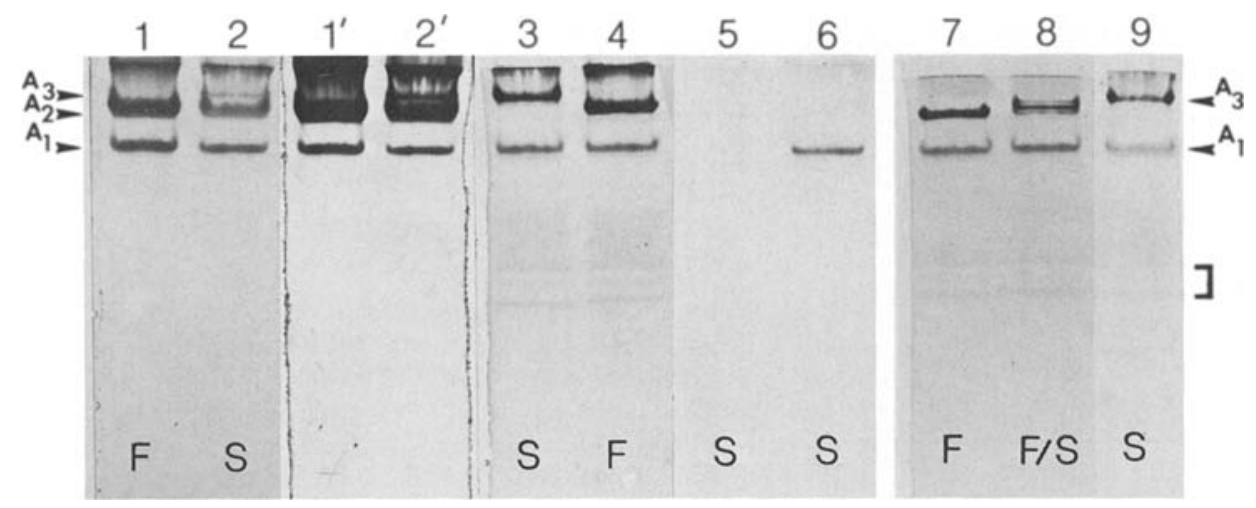

Fig. 3. Slab gels showing the positions of the $A_{1}, A_{2}$, and $A_{3}$ phenoloxidase bands after activation in P-activator (lanes 1, 2, 6) and $50 \%$ 2-propanol (lanes $3,4,5,7-9$ ). Gels 1 and 2 were incubated in dopa; 3, 4, and 7-9 were incubated in dopa $+\mathrm{Cu}^{++}$; 5 and 6 were incubated in tyrosine. 1 and 2 were photographed after $1 \mathrm{~h}$ and after $18 \mathrm{~h}\left(1^{\prime}, 2^{\prime} ;\right.$ a lighter print) incubation in dopa. F and $\mathrm{S}$ are extracts from homozygotes; $\mathrm{F} / \mathrm{S}$ from heterozygotes. The bracket shows the position of the faint bands that appear in propanolactivated gels incubated overnight in dopa containing $\mathrm{Cu}^{++}$

showed activity only in the most anodal band which corresponds in relative position to the monophenoloxidase band ( $A_{1}$, tyrosinase) described by Mitchell and Weber (1965) (Fig. 3, lane 6). We assume that the two remaining diphenoloxidase bands are the $\mathrm{A}_{2}$ and $\mathrm{A}_{3}$ components, the latter being the least anodal. The $A_{3}$ component showed minor activity after incubation in $\mathrm{P}$-activator while $\mathrm{A}_{2}$ gave a strong reaction (lane 2). Gels with Dox extracts showed only two bands after treatment with P-activator and dopa incubation, one band corresponding in position to the $A_{1}$ band of $O r e-R$ and one near the level of $\mathrm{A}_{2}$. No band appeared at the $\mathrm{A}_{3}$ position even if the gels were incubated overnight in dopa (Fig. 3, lanes 1 and 1').

No tyrosinase band appeared in propanol-activated gels containing Ore- $R$ proenzymes (Fig. 3 , lane 5), and only the $A_{1}$ and $A_{3}$ bands were present in propanol-activated gels incubated in dopa (Fig. 3, lane 3). After propanol activation and dopa incubation, $D o x^{\mathrm{F}}$ extracts also showed only two bands, an $A_{1}$ band and the $F$ band. We conclude that Dox codes for the $\mathrm{A}_{3}$ component of the phenoloxidase complex and this qualifies its designation as Dopa oxidase-3 $($ Dox-3).

Activity bands in P-activated gels appeared within $5 \mathrm{~min}$ and were intense within $2 \mathrm{~h}$. The appearance of bands in dopa was slower when propanol was the activator than with P-activator, and the bands appeared first as reddish brown and blackened within several hours. If $\mathrm{Cu}^{++}$was added to the dopa solution and incubation was extended overnight to intensify the bands, an additional faint band corresponding in position to the $\mathrm{A}_{2}$ band of $\mathrm{P}$-activated gels appeared. Also, 2-3 bands that had migrated ahead of the $A_{1}$ band showed weak staining (Fig. 3, lanes 3, 4, $7-9)$. The positions of these bands were the same in Ore-R, Dox $-3^{\mathrm{F}}$, and in $F / S$ heterozygotes. These bands probably correspond to the diffuse blackening in the anodal region of disk gels. If $\mathrm{Cu}^{++}$was included in the tyrosine incubation mixture and the gels were incubated overnight, faint bands corresponding in position to the three A components were visible. We assume this activity was due to oxidation of tyrosine in the presence of $\mathrm{Cu}^{++}$(Foster 1950).

\section{Phenoloxidases in hemolymph}

Third instar $t u(1) S z^{\text {ts }}$ larvae have more hemocytes in their hemolymph than Ore-R larvae since the hemocytes in the first pair of lymph glands are released precociously in the mutant larvae (R.M. Rizki and T.M. Rizki 1984). Hemolymph samples of $t u(1) S z^{\text {ts }}$ larvae were electrophoresed in slab gels with Ore- $R$ cell-free extracts as controls. Following treatment with $\mathrm{P}$-activator the gels were incubated in dopa. The three A components with the same electrophoretic mobilities were present in both samples. However, this observation does not establish that hemolymph and cuticular prophenoloxidases are the same. It is possible that the enzyme detected in larval extracts is solely hemolymph enzyme and the cuticular proenzymes are not released by the method used for enzyme extraction.

\section{Intracellular localization of phenoloxidase}

The prophenoloxidases of the crystal cells are activated in situ in $B c$ mutant larvae, and as a consequence, melanization and crosslinking of crystal cell proteins results in destruction of this cellular source of hemolymph phenoloxidases (Rizki et al. 1980). There is no detectable phenoloxidase activity in $B c / B c$ hemolymph. To determine whether crystal cell prophenoloxidases can be activated in vitro by propanol and $\mathrm{P}$-activator, hemolymph samples of $t u(1) S z^{\mathrm{ts}}$ and $l z^{\mathrm{rfg}}$ males were fixed on microscope slides, activated, and incubated in buffered dopa.

There was no blackening of hemocytes in $l z^{\mathrm{rfg}}$ samples even if the cells were incubated in dopa for $20 \mathrm{~h}$. In $t u(1) S z^{\text {ts }}$ samples melanization appeared in the crystal cells within $30 \mathrm{~min}$. No other hemocyte types were blackened. The darkening within the crystal cells was clearly visible in the paracrystalline inclusions (Fig. $4 \mathrm{a}, \mathrm{b}$ ). After $2 \mathrm{~h}$ incubation in dopa the entire cell was darkly pigmented. In P-activated samples the blackening remained restricted to the crystal cells even after $20 \mathrm{~h}$ incubation (Fig. 4d). Similar incubation of propanol-activated samples showed diffusion gradients such that plasmatocytes, lamellocytes, and coagulated hemolymph components near crystal cells were melanized (Fig. 4c). Presumably, propanol treatment affects the permeability of the plasma membrane allowing leaching of the activated enzymes from the crystal cell. The surrounding cells serve as sites for pigment deposition.

Crystal cells treated with either activator and incubated in tyrosine developed a faint brownish color that remained weak even after $20 \mathrm{~h}$ incubation. It was not possible to determine whether this slight coloration initiated from the 

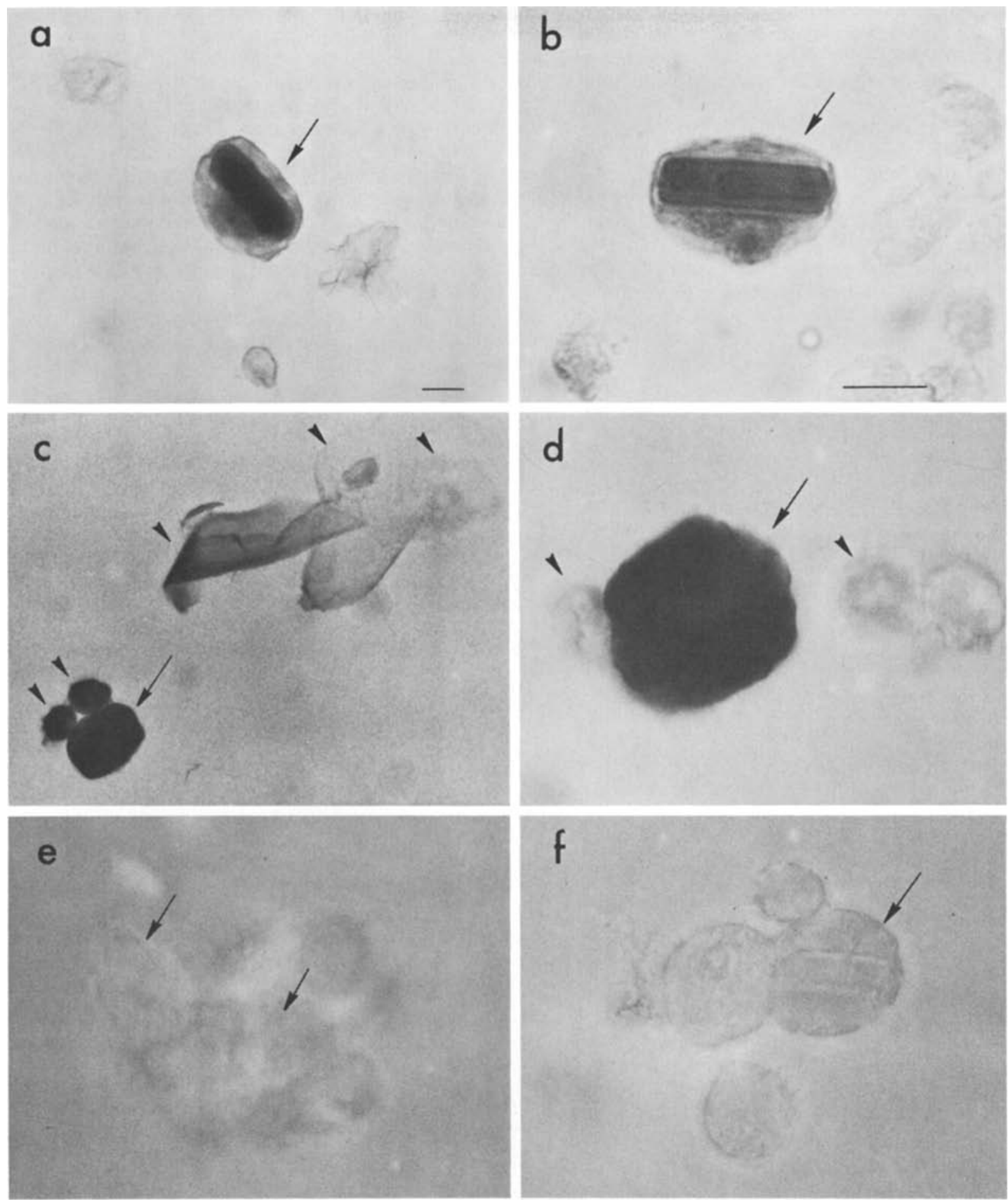

Fig. 4a-f. In situ activation of phenoloxidases in hemocytes. The arrows point to crystal cells; the arrowheads to plasmatocytes and lamellocytes. a Crystal cell incubated in dopa after treatment with 2-propanol. The paracrystalline inclusion is blackened. b A crystal cell treated with P-activator and incubated in dopa shows blackening of the paracrystalline inclusion. c Hemocyte sample activated in propanol and incubated in dopa for $20 \mathrm{~h}$. A gradient of melanization is apparent from the large crystal cell in the lower left to the two small plasmatocytes lying nearby and the thin lamellocytes at the upper right. $\mathbf{d}$ There is no melanization of the plasmatocytes in the immediate vicinity of a crystal cell treated with P-activator and incubated for $20 \mathrm{~h}$ in dopa. e Control: P-activated hemocytes incubated in buffer. f Control: nonactivated hemocytes incubated in dopa. Scale bars represent $10 \mu \mathrm{m} ; \mathbf{b}$ and $\mathbf{d - f}$ are at the same magnification

paracrystalline inclusions. Fixed cell samples incubated in dopa without prior activation did not develop melanin, nor did propanol-activated and $\mathrm{P}$-activated samples that remained in buffer without substrates (Figs. $4 \mathrm{e}$ and f).

\section{Discussion}

The structural gene coding for $\mathrm{A}_{3}$ proenzyme, a component of the phenoloxidase complex described and characterized 
by Mitchell and Weber (1965) is Dox-3. Heterozygotes for the Slow (S) and Fast (F) Dox-3 alleles show a hybrid band with intermediate mobility and higher activity than either the $\mathrm{S}$ or $\mathrm{F}$ band. This agrees with the expected distribution for dimeric enzymes: $(\mathrm{S}+\mathrm{F})^{2}=\mathrm{SS}+2 \mathrm{SF}+\mathrm{FF}$. The $\mathrm{F}$ variant has no apparent effect on the mobility of the $A_{1}$ or $\mathrm{A}_{2}$ proenzymes. Therefore, the latter proteins must be coded by gene(s) other than Dox-3.

To map the Dox-3 gene by formal recombination analysis was not feasible because larval markers in the $b-p r$ interval are not available. Therefore, we established the position of the Dox-3 locus between $r d o$ (53.1) and $h k$ (53.9) by electrophoretic examination of homozygous single-crossover stocks. More accurate ordering of the Dox-3 locus was achieved using overlapping deficiencies and the sequence of markers surrounding $r d o: d l ~ l(2) B l d r d o ~ M(2) m$ $T f t h k$ (T.R.F. Wright, personal communication). This analysis narrowed the position of the locus to between $r$ do and $M(2) \mathrm{m}$. Another gene that affects phenoloxidase activity, tyr-1 (Lewis and Lewis 1963), is located at $52.4 \pm 0.5$ and is thus close to $r d o(53.1)$ and Dox-3. Since the activity level of the Dox-3 product is modified by tyr-1 which also affects overall phenoloxidase levels and Dox-3/tyr-1 trans heterozygotes are complementary, we suggest that tyr-1 is a modifier of phenoloxidase activity rather than a structural gene for these proenzymes as originally proposed by Lewis and Lewis (1963).

The $l z$ locus also modifies the levels of phenoloxidase activity. This study confirms that enzyme activity is absent in $l z^{\mathrm{rg}}$ (Warner et al. 1974) and $l z^{\mathrm{s}}$ larvae (Peeples et al. 1969). Crystal cells do not differentiate in these $l z$ alleles (Rizki and Rizki 1981). It is likely that the $l z$ locus which has a wide variety of effects on ectodermal derivatives such as the eye, leg, and female genital discs (Anderson 1945; Chovnick and Lefkowitz 1956; Green and Green 1956) also influences the differentiation of mesodermal cell clones that give rise to the larval crystal cells. Thus, the effects of the $l z$ locus on phenoloxidase activity are not via a direct role in proenzyme synthesis. Rather, this locus affects the differentiation of the larval hemocytes that carry the proenzymes. The presence of crystal cells can be traced to the mid-embryonic stage using the $B c$ mutant which causes melanization of the cells (Rizki et al. 1980), so the $l z^{+}$product must be active before this time.

The correlation between phenoloxidase activity and the presence of paracrystalline inclusions within the crystal cells of $l z$ mutants agrees with the in situ localization of prophenoloxidase in the paracrystalline inclusions. It is also clear from the latter that the phenoloxidase activity in the hemolymph is confined to the crystal cells. Further, at least one of the prophenoloxidases is present in the paracrystalline inclusions of these cells.

We hoped to visualize the PHOX component described by Batterham and McKechnie (1980) in propanol-activated gels by adding $\mathrm{Cu}^{++}$to the substrate solutions. However, we found 2-3 bands appearing anodal to the A components after overnight incubation in dopa solution containing $\mathrm{Cu}^{++}$. One of these bands may be the PHOX component. Alternatively, the delayed blackening may be due to selective melanization of proteins by dopaquinone generated in the incubation mixture containing $\mathrm{Cu}^{++}$(Foster 1950).

The differential activation of the prophenoloxidases by propanol and P-activator provided a means of distinguishing the $A_{2}$ and $A_{3}$ components, thereby facilitating identifi- cation of the fast $\mathrm{A}_{3}$ variant. The activation of dopa oxidase activity of $A_{1}$ and $A_{3}$ by propanol and the strong activation of both the $\mathrm{A}_{1}$ and $\mathrm{A}_{2}$ components by $\mathrm{P}$-activator indicates shared qualities of the $A_{2}$ and $A_{3}$ components with $A_{1}$ dopa oxidase activity. On the other hand, the monophenoloxidase (tyrosinase) activity of the $A_{1}$ component is unique and not shared by $A_{2}$ or $A_{3}$. These interrelationships may indicate that the proenzymes are products of an evolutionary family of genes; if so, which one is the ancestral form? In this regard, it is interesting that the lepidopteran Bombyx mori, representing a more primitive insect group than the dipteran Drosophila, has a single prophenoloxidase (Ashida and Dohke 1980).

Acknowledgements. We thank Dr. T.R.F. Wright for providing unpublished information on deficiencies and comments on the manuscript. Research was supported by NIH Grant AG-01945.

\section{References}

Anderson RC (1945) A study of the factors affecting fertility of lozenge pseudoalleles in Drosophila melanogaster. Genetics $30: 280-296$

Ashida M, Dohke K (1980) Activation of pro-phenoloxidase by the activating enzyme of the silkworm, Bombyx mori. Insect Biochem 10:37-47

Batterham P, McKechnie SW (1980) A phenol oxidase polymorphism in Drosophila melanogaster. Genetika 54:121-126

Brunet PCJ (1980) The metabolism of the aromatic amino acids concerned in the cross-linking of insect cuticle. Insect Biochem $10: 467-500$

Chovnick A, Lefkowitz RJ (1956) A phenogenetics study of the lozenge pseudoalleles in Drosophila melanogaster. I. Genetics $41: 79-92$

Foster M (1950) Non-enzymatic oxidation of tyrosine and dopa. Proc Natl Acad Sci USA 36:606-611

Green MM, Green KC (1956) A cytogenetic analysis of the lozenge pseudoalleles in Drosophila melanogaster. Z Induct Abstamm Vererbungsl 87:708-721

Lewis HW, Lewis HS (1963) Genetic regulation of dopa oxidase activity in Drosophila. Ann NY Acad Sci 100:827-839

Lindsley DL, Grell EH (1968) Genetic variations of Drosophila melanogaster. Carnegie Inst Wash Publ 627

Mishell BB, Shiigi SM (1980) Selected methods in cellular immunology. W.H. Freeman and Company, San Francisco

Mitchell HK, Weber UM (1965) Drosophila phenol oxidases. Science 148:964-965

Peeples E, Geisler A, Whitcraft CJ, Oliver CP (1969) Activity of phenol oxidases at the puparium formation stage in development of nineteen lozenge mutants of Drosophila melanogaster. Biochem Genet 3:563-569

Rizki TM (1956) Blood cells of Drosophila as related to metamorphosis. In: Campbell FL (ed) Physiology of insect development. University of Chicago Press, pp 91-94

Rizki RM, Rizki TM (1984) Selective destruction of a host blood cell type by a parasitoid wasp. Proc Natl Acad Sci USA $81: 6154-6158$

Rizki TM, Rizki RM (1959) Functional significance of the crystal cells in the larva of Drosophila melanogaster. J Biophys Biochem Cytol 5:235-240

Rizki TM, Rizki RM (1980) Developmental analysis of a temperature-sensitive mutant in Drosophila melanogaster. Wilhelm Roux's Arch Dev Biol 189:197-206

Rizki TM, Rizki RM (1981) Alleles of $l z$ as suppressors of the $B c$-phene in Drosophila melanogaster. Genetics 97:S90.

Rizki TM, Rizki RM (1984) The cellular defense system of Drosophila melanogaster. In: King RC, Akai H (eds) Insect ultrastructure, vol 2. Plenum Publishing Corporation, New York, pp 579-604 
Rizki TM, Rizki RM, Grell EH (1980) A mutant affecting the crystal cells in Drosophila melanogaster. Wilhelm Roux's Arch Dev Biol 199:91-99

Seybold WD, Meltzer PS, Mitchell HK (1975) Phenol oxidase activation in Drosophila: A cascade of reactions. Biochem Genet 13:85-108

Tokunaga C (1967) Recombination frequency between Tufted and Bristle. Drosophila Inform Serv 42:40

Warner CK, Grell EH, Jacobson KB (1974) Phenol oxidase activity and the lozenge locus of Drosophila melanogaster. Biochem Genet 11:359-365

Woodruff RC, Ashburner M (1979) The genetics of a small autosomal region of Drosophila melanogaster containing the structural gene for alcohol dehydrogenase. II. Lethal mutations in the region. Genetics 92:133-149

Wright TRF, Hodgetts RB, Sherald AF (1976) The genetics of dopa decarboxylase in Drosophila melanogaster. I. Isolation and characterization of deficiencies that delete the dopa-decarboxylase-dosage-sensitive region and the $\alpha$-methyl-dopa hypersensitive locus. Genetics 84:267-285

Communicated by $\mathrm{K}$. Illmensee

Received March 5/June 5, 1985 